\title{
The lost 1896 Clark X-ray images
}
IN BRIEF
- Records an important addition to the history of early dental radiographs.
- Shows the diagnostic value of dental radiology at the earliest stage.
- Demonstrates the archival value of dental radiographs.
- Provides a reminder of the need for radiation safety.
- Indicates the value of dental radiographs in encouraging preventive dentistry.

This paper examines the lost Clark X-ray images and the birth of dental radiographs. Whilst there were important developments arising at the end of the nineteenth century with regard to radiological processes, it was a time when the need for radiation safety was unknown resulting in harmful and often fatal consequences. We are therefore indebted to our predecessors who, through these discoveries, have shaped today's methods and safe practising of radiography.

\section{INTRODUCTION}

The images described in this paper and reproduced in Figure 1 were made in London in 1896, in the first year of worldwide experimentation following Wilhelm Conrad Röntgen's (1845-1923) discovery and naming of X-rays on 8 November 1895, and the publication of Über Eine Neue Art von Strahlen in December. ${ }^{1}$ (This landmark publication is now freely available online.) Otto Walkhoff (1860-1934) of Brunswick is credited with arranging the first dental radiographs, of his own teeth, just two weeks after Röntgen's discovery. The physicist/operator was his colleague Friedrich Giesel (1852-1927), and Walkhoff used glass plates with an exposure time of 25 minutes. $^{2}$ The honours for the first publication relating to dental radiology are credited to Frank Harrison (1852-1912) of Sheffield, ${ }^{3}$ whose illustrated papers were published in the British Dental Journal in May $^{4}$ and June ${ }^{5}$ 1896. His exposure times were ten minutes for the images illustrated in Figure 2.

\section{PROVENANCE}

The photographs of the original Clark images (a mixture of prints and $35 \mathrm{~mm}$ slides), were taken in 1982 to illustrate

\footnotetext{
'Honorary Research Fellow, History of Dentistry, King's College London Dental Institute

Correspondence to: Malcolm Bishop

Email: malcolmbishop57@btinternet.com
}

\section{Refereed Paper}

Accepted 7 December 2012

DOI: $10.1038 /$ sj.bdj.2013.155

${ }^{\circ}$ British Dental Journal 2013; 214: 187-190

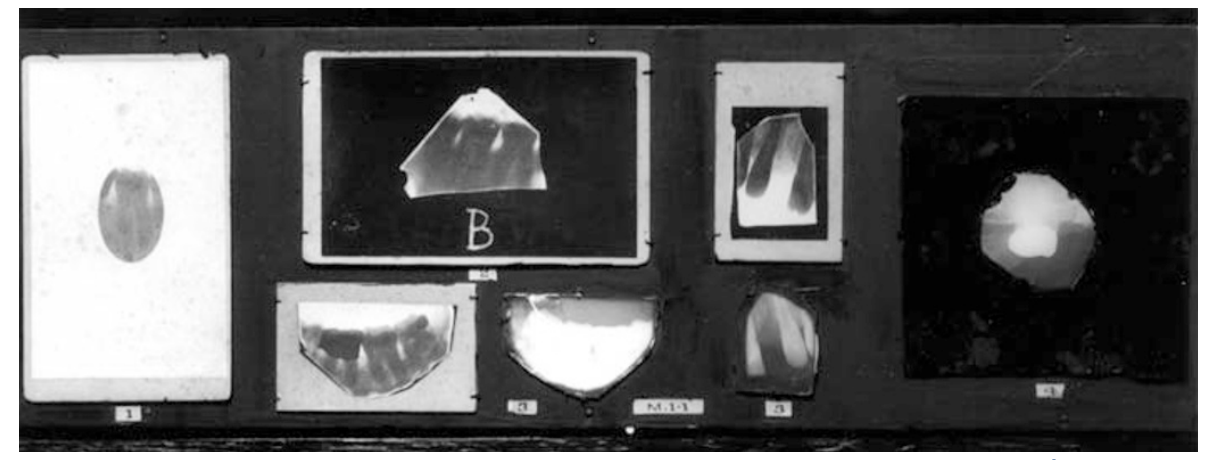

Fig. 1 The Clark radiographs and skiagraphs on their light-box. Photographed 1982/3

an MSc Report ${ }^{6}$ and to provide teaching material for dental students at Kings College Hospital Dental School (now part of GKT). This has proved to be fortunate as the originals, which were at the time in the Odontological Museum at the Royal College of Surgeons, cannot now be found. It was the intention of the curator in 1982 to remount the original material and this may have led to subsequent dispersal. The light-box was identified by the legend 4.1.1., but no key to the individually numbered images was available.

No detail of the radiologist is known, beyond the personal communication in 1982 from Professor A. E. W. 'Loma' Miles (1912-2008) that he was Clark or Clarke and experimenting at the London Hospital.

\section{TECHNICAL DETAILS AND TECHNICAL PROGRESS}

The equipment needed to produce the new rays was already available in physics laboratories in England and elsewhere using tubes invented by William

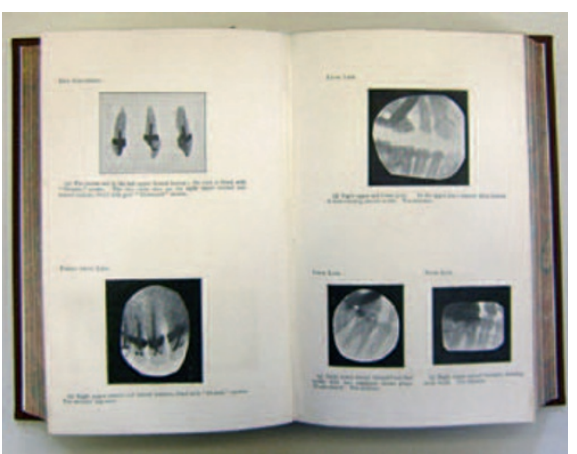

Fig. 2 The Frank Harrison skiagraphs (his term) illustrated in the $B D J$ of May 1896. By kind permission of the Library of the British Dental Association

Crookes (1832-1919) and developed between 1869-1875. For dental imaging it was fortunate that the processes of photography were well established and could be transferred to radiology. This allowed an image to be developed and kept rather than just be seen transiently on fluorescent screens, although in time dental-mirror sized screens were made for intra-oral use. However, those wishing to take dental radiographs were faced with 
more difficulties to overcome than those taking medical images, as they could not use standard size glass plates and standard light-proof cassettes, as seen under the foot of the subject seen in the 1896 apparatus used by Rowland (Fig. 3).

The very first dental experimenters, who like Clark produced intra-oral images, had to cut down or break up the plate with its light-sensitive emulsion layer (Fig. 4) to an appropriate size, deal with the sharp edges, wrap the piece of glass in black paper and then waterproof it in rubber dam efficiently enough to survive as much as 25 minutes in the mouth. All this had to be done in the dark or under safelight conditions and was not always successful. There is a suggestion of light fogging adjacent to the sharp corners of the glass on the skiagraph labelled B in Figure 1 and in view of the jagged nature of the image, it would not be surprising if the paper and rubber dam had been perforated by the original glass - it is to be hoped that the patient or volunteer was not also perforated.

Such mechanical difficulties were quickly overcome by the adoption of flexible film base. Before Harrison lectured and wrote in June 1896, he had seen the advantage and convenience of 'Eastman's Kodac' (sic) films and had taken the first step which was to lead to a halving of the exposure time, by folding the film in half to produce a double negative (made to produce a duplicate).

Exposures were long and the relationship of the teeth and imaging medium had to be kept constant (for an unfocused tube as source absolute immobility of the patient was not so important). To locate and hold his films in the mouth Harrison used a stent on which the patient bit - thereby incidentally producing the first 'bitewing' type images. As yet bisecting angle or paralleling techniques had not been introduced, but the Clark image of an upper molar shows that from the earliest stage the 'feel' for angling the $\mathrm{X}$-ray source to achieve a practical result for maxillary molar root lengths had been managed successfully.

The pioneers were not discouraged and even though the results seen here can be faulted for coverage and image quality, the excitement of seeing what had been produced may well be imagined. Even a cursory comparison between the Walkhoff,

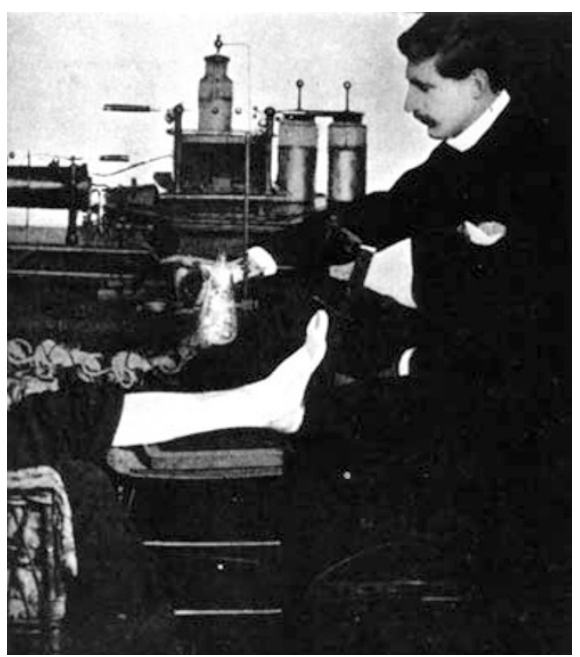

Fig. 3 Sydney Donville Rowland (1872-1917) of Kings College Hospital shown using a Crookes' tube and photographic cassette to radiograph an ankle. Archives of Clinical Skiagraphy 1896

the Clark and the Harrison images underlines the rapid progress in dental radiographic imaging that was being made in the first months. Specialised equipment was also being introduced, and the $B D J$ carried an announcement of an improved Crookes' tube later in $1896 .^{7}$

\section{MOUNTING AND VIEWING THE IMAGES}

Of considerable interest is that it would appear from the Clark images that for dental radiography the use of the negative, viewed by transmitted light, was being considered alongside the positive print or skiagraph, which was made from the negative and then viewed by reflected light. (The term skiagraph is used here, as Rowland's preferred term, ${ }^{8}$ to distinguish these prints from the negative film or glass radiographs, although for a while the terms were interchangeable). It is not clear whether Harrison had taken the step of viewing negatives without printing them, but in his text he describes a lecture slide of the developing dentition in a seven-year-old girl as a mirror image of the print reproduced in the $B D J^{5}$ (Fig. 5).

All Harrison's illustrations in the $B D J$ are positive skiagraphs and experimenters used to photography would have regarded the step to print as a natural one, with dense substances like bone or teeth appearing dark and soft tissue and air appearing light. The result would also have been both easier to save in the subject's clinical records and easily reproduced for sharing with colleagues by post or in printed book form. Two of the Clark skiagraphs seen in Figure 1 appear to have been contact printed onto full sized cartes-de-visite, a medium readily available from photographic suppliers. As the thickness of the other skiagraphs is comparable, it is likely that these were cut down from the same stock.

In the Clark collection of glass negatives part of the quality of the images is the result of masking the radiographs using thick black paint, but as this might have been done when the light-box was set up it cannot be claimed that the original experimenters discovered how important this was for reading the image. However, it might be expected that they would have found this out very quickly. To decide which of the two, negative or print, was preferable for clinical use was just one of the many decisions to be made. A comparison for this purpose may be the reason that the glass negatives were retained in the case of the Clark images (Fig. 6a and b).

Other protocols, which are not to be found in this collection, also had to be developed. When at a later and unknown date the radiographs and skiagraphs were mounted on the light-box the orientation of the items was not in accordance with any clear convention. This is consistent with the way they were taken and used at the time. Once the glass pieces (or film for Harrison) with their emulsion coating had been wrapped in black paper and rubber dam they had no particular back or front. Identification of the image with a tooth or set of teeth depended entirely on the clinical notes. The Harrison skiagraph of the seven-year-old girl may be of her right side, as earlier in his text he says that this was more convenient when X-raying his assistant, but he does not say so, and as already discussed, the printed image does not match the text. Of the Clark examples the image labelled B in Figure 1 may be of upper teeth rather than as mounted.

\section{THE IMPORTANCE OF THE CLARK IMAGES}

The clearest and perhaps both now and originally, the most interesting of the images is the glass negative labelled ' 4 ' on the right side of Figure 1 (Fig. 7). This radiograph alone would have served to demonstrate the revolutionary nature 


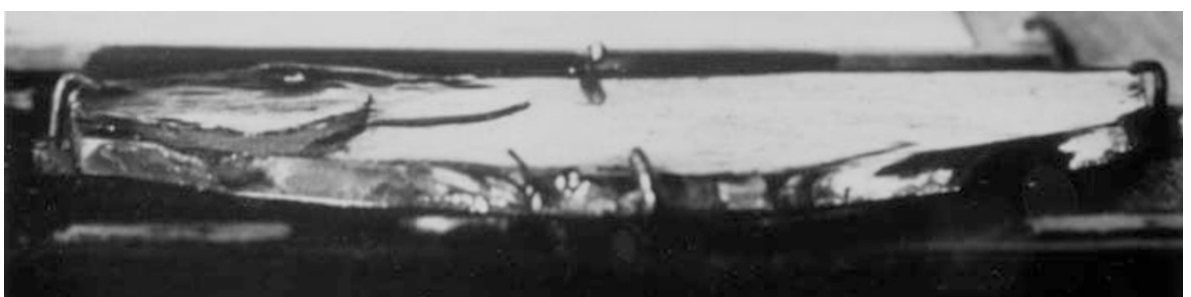

Fig. 4 Emulsion layer separating from the glass plate

of this new technique available to dentists, and ensured its continued progress in the face of all difficulty. Not only is the artificial crown clearly demonstrated (in this case apparently cast metal and well fitting), but a root filling in the palatal or disto-buccal root may be seen. Part of what appears to be a retained root further anteriorly is also shown. As for hard and soft tissue anatomy, the tip of the coronoid process is imaged, the reticular pattern of the alveolar bone is clear, as is the gingival soft tissue. These features indicate a live subject or cadaver rather than a dry skull. The floor of the maxillary antrum may be distinguished (faintly either as a result of opacity in the antrum or because the zygoma shadow overlies it).

Bearing in mind that we are here looking at a printed reproduction of a photographic copy made 30 years ago, when the original image was already 86 years old, the archival nature and quality of dental radiographs is clear. This again was something entirely new at the time - for the first time dentists could see within and around the teeth and could obtain a record for future reference, comparison and research.

\section{CAUTIONARY POSTSCRIPT}

Initial excitement was quickly followed by a sobering realisation of the dangers and risks to patient and operator.

That the physical dangers of this wonderful new technique were not limited to cuts from sharp-edged glass were soon realised. In 1896 the radiation was soft at low $\mathrm{kV}$, with no hardening of the beam or collimation and where teeth were being imaged the skin dose to the face of the patient was very high, resulting in burns and hair loss. Harrison, writing in June 1896 describes a severe burn sustained by his assistant and its ongoing effects. ${ }^{5}$ This, as it turned out, was not the end of the hazards, but as yet the capacity of the new rays for inducing malignancies and for genetic damage was unknown.
The greater hazard was to the operator - whose vulnerable position is well seen in Figure 3. Röntgen himself used lead shielding extensively and was in any case not subject to the long and multiple exposures of the early clinicians and their assistants who did not use shielding. Several hundred of these new radiologists lost their lives to radiation-induced malignancies ${ }^{9}$ and dentists who held film in patient's mouths developed intractable dermatitis and malignancies in the exposed digits. Rowland, who is seen in Figure 3 using a Crookes tube with no shielding, died in France in 1917 of cerebro-spinal fever, aged 45, while serving as a Major in the Royal Army Medical Corps, ${ }^{10}$ so there is no evidence that he was one of the early $\mathrm{X}$-ray martyrs.

More unexpected perhaps, as an unintended hazardous result, was that the flood of information suddenly released about the extent of damage to the bone of the jaws as a result of acute and more importantly chronic, dental infection, led for a considerable while to the discrediting of much of the more advanced forms of dentistry; root filling and crowns in particular. To borrow the words of William Hunter, what were seen on radiographs were "mausoleums of gold covering a mass of corruption. ${ }^{11}$

Harrison showed three extracted teeth $\mathrm{X}$-rayed in vitro. They have crowns on short posts and although the root canals appear to have been instrumented and enlarged there is no evidence of any radiopaque root filling. One of them shows apparent apical resorption with a pattern suggesting the previous presence of a granuloma. This is in contrast to another of his images taken 'from life' where crowned incisor teeth appear to have well filled pulp cavities.

The rapidly expanding radiographic record added enormous weight to the concept of Miller and Hunters' theories of focal infection originating from the mouth. ${ }^{12,13}$ This led to dental clearances

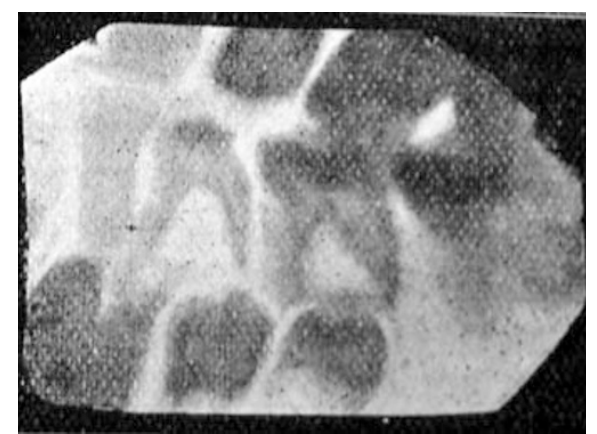

Fig. 5 Skiagraph of a seven-year-old girl - Harrison 1896

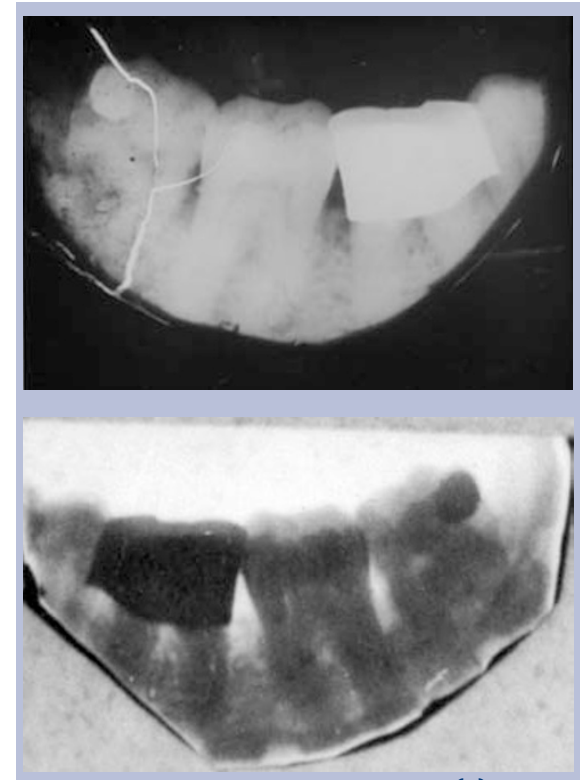

Fig. 6 Radiograph of lower molars (a) glass and emulsion; (b) skiagraph print on card

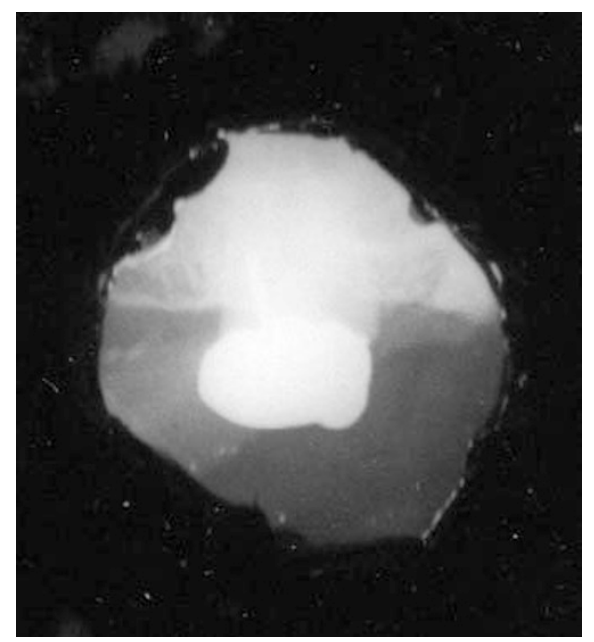

Fig. 7 Radiograph of a root filled upper molar tooth

being performed for many medical conditions. It was not for many years that dental radiology helped to lead to a balanced assessment of the link between dental disease and systemic illness and for the advanced conservative restoration of 
teeth, where prevention of dental disease had failed, to become acceptable ethical treatment again.

\section{SUMMARY}

It is tempting to assert that having been taken on broken glass plates the Clark images pre-date, or are at least contemporary with, the Harrison images. However, all that can be said with certainty is that if they do post-date the Harrison images, Clark had either not read in the $B D J$ or not taken in Harrison's use of readily available Kodak film. Whatever the case may be, these images are of great significance, dating from the birth of dental radiology, and as with Harrison's, showing an early grasp of the significance of the new tool available to the profession. In them can be seen much of what the future profession would come to regard as essential, as purposebuilt dental X-ray equipment was devised, and, though it took many years, for safe(r) operating procedures to be developed.

Perhaps most importantly, the obstacles to be overcome and the information yielded drove on the policy of evidencebased prevention. These X-ray pictures show bone loss as well as decay, restorations and carious cavities.

Finally, the photographs and slides have been donated to the Museum of the British Dental Association and if any reader has information about the identity of Clark(e), please inform the BDA Museum curator.

The kind assistance of Peter Hirschmann for information about Harrison, about whom a recent paper has also been published in the $B D J,{ }^{14}$ and of the librarians of the $B D A$ is gratefully acknowledged.

1. Röntgen W C. Über Ein Neue Art von Strahlen. Würtzburg: University Press, 1895. Online article available at $h t t p: / / a r c h i v e . o r g / d e t a i l s / e i n e-$ neueartvons00regoog (accessed January 2013).

2. Busch U. Newsletter of the radiology history and heritage charitable trust. Radiology History and Heritage Charitable Trust 1998; 10: 7-8. Online article available at http://www.docstoc.com/docs/4717216/ The-Radiology-History-Heritage-Charitable-Trust-TheNewsletter-of (accessed January 2013).

3. Hirschmann P. Frank Harrison (1852-1912). Den Hist 2006; 43: 62-66.

4. Harrison F. The new photography and its application to dental practice. Br Dent J 1896; 17: 343-344.

5. Harrison F. The ' $x$ ' rays in the practice of dental surgery. Br Dent J 1896: 17: 624-628.

6. Bishop M G H. Dental and maxillo-facial radiographic imaging methods. Unpublished MSc report, 1983.

7. The new photography - new focus tube (Messrs. Brady and Martin). Br Dent J 1896; 17: 692.

8. Bishop P J. The evolution of the British Journal of Radiology. Brit J Radiol 1973; 46: 833-836. Online article available at http://bjr.birjournals.org/content/46/550/833 (accessed January 2013).

9. The John Rylands University Library. Material relating to the radiation martyrs. Online article available at http://archives.li.man.ac.uk/ead/search?operation=ful Etrecid=gb133gut-gut-3-5 (accessed January 2013).

10. Sydney Donville Rowland obituary notice. Nature 1917; 99: 67-68

11. Hunter $W$. The role of sepsis and antisepsis in medicine. Lancet 1910; 1: 79-86.

12. Miller W D. The human mouth as a focus of infection. Dental Cosmos 1891; 33: 689-713.

13. Hunter W. Oral sepsis as a cause of disease. BMJ 1900; 1: 215-216.

14. Figures $K$, Smith C. A profile of Frank Harrison: a pioneering Sheffield dentist from 100 years ago. Br Dent J 2012; 213: 405-408. 